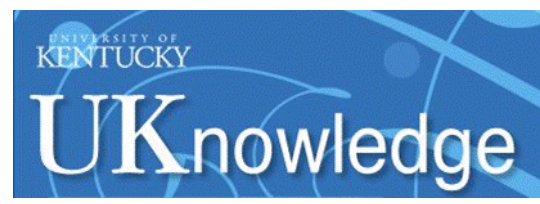

University of Kentucky

UKnowledge

3-15-2012

\title{
Inhibition of Fatty Acid Synthase Attenuates CD44-Associated Signaling and Reduces Metastasis in Colorectal Cancer
}

\author{
Yekaterina Y. Zaytseva \\ University of Kentucky, yyzayt2@uky.edu \\ Piotr G. Rychahou \\ University of Kentucky, piotr.rychahou@uky.edu \\ Pat Gulhati \\ University of Kentucky \\ Victoria Allison Elliott \\ University of Kentucky, victoria.elliott@uky.edu \\ William Conan Mustain \\ University of Kentucky,wc.mustain@uky.edu
}

See next page for additional authors

Follow this and additional works at: https://uknowledge.uky.edu/markey_facpub

Part of the Cancer Biology Commons, and the Oncology Commons

Right click to open a feedback form in a new tab to let us know how this document benefits you.

\section{Repository Citation}

Zaytseva, Yekaterina Y.; Rychahou, Piotr G.; Gulhati, Pat; Elliott, Victoria Allison; Mustain, William Conan; O'Connor, Kathleen; Morris, Andrew J.; Sunkara, Manjula; Weiss, Heidi L.; Lee, Eun Young; and Evers, B. Mark, "Inhibition of Fatty Acid Synthase Attenuates CD44-Associated Signaling and Reduces Metastasis in Colorectal Cancer" (2012). Markey Cancer Center Faculty Publications. 122.

https://uknowledge.uky.edu/markey_facpub/122

This Article is brought to you for free and open access by the Markey Cancer Center at UKnowledge. It has been accepted for inclusion in Markey Cancer Center Faculty Publications by an authorized administrator of UKnowledge. For more information, please contact UKnowledge@lsv.uky.edu. 


\title{
Inhibition of Fatty Acid Synthase Attenuates CD44-Associated Signaling and Reduces Metastasis in Colorectal Cancer
}

\author{
Digital Object Identifier (DOI) \\ https://doi.org/10.1158/0008-5472.CAN-11-4057 \\ Notes/Citation Information \\ Published in Cancer Research, v. 72, issue 6, p. 1504-1517. \\ (c) 2012 American Association for Cancer Research.
}

The copyright holder has granted the permission for posting the article here.

The document available for download is the authors' post-peer-review final draft of the article.

\section{Authors}

Yekaterina Y. Zaytseva, Piotr G. Rychahou, Pat Gulhati, Victoria Allison Elliott, William Conan Mustain, Kathleen O'Connor, Andrew J. Morris, Manjula Sunkara, Heidi L. Weiss, Eun Young Lee, and B. Mark Evers 


\title{
Inhibition of Fatty Acid Synthase Attenuates CD44-Associated Signaling and Reduces Metastasis in Colorectal Cancer
}

\author{
Yekaterina Y. Zaytseva ${ }^{1,2}$, Piotr G. Rychahou ${ }^{1,2}$, Pat Gulhati ${ }^{1,2}$, Victoria A. Elliott ${ }^{1}$, William \\ C. Mustain ${ }^{1,2}$, Kathleen O'Connor ${ }^{1}$, Andrew J. Morris ${ }^{4,5}$, Manjula Sunkara ${ }^{4,5}$, Heidi L. \\ Weiss $^{1,2}$, Eun Y. Lee ${ }^{1,2,3}$, and B. Mark Evers ${ }^{1,2}$ \\ ${ }^{1}$ Markey Cancer Center, University of Kentucky, Lexington, Kentucky, USA \\ ${ }^{2}$ Department of Surgery, University of Kentucky, Lexington, Kentucky, USA \\ ${ }^{3}$ Department of Pathology and Laboratory Medicine, University of Kentucky, Lexington, Kentucky, \\ USA \\ ${ }^{4}$ Division of Cardiovascular Medicine, University of Kentucky, Lexington, Kentucky, USA \\ ${ }^{5}$ Gill Heart Institute, University of Kentucky, Lexington, Kentucky, USA
}

\begin{abstract}
Fatty Acid Synthase (FASN) and ATP-citrate lyase (ACLY), key enzymes of de novo lipogenesis, are significantly upregulated and activated in many cancers and portend poor prognosis. Even though the role of lipogenesis in providing proliferative and survival advantages to cancer cells has been described, the impact of aberrant activation of lipogenic enzymes on cancer progression remains unknown. In this study, we found that elevated expression of FASN is associated with advanced stages of colorectal cancer (CRC) and liver metastasis, suggesting that it may play a role in progression of CRC to metastatic disease. Targeted inhibition of lipogenic enzymes abolished expression of $\mathrm{CD} 44$, a transmembrane protein associated with metastases in several cancers including CRC. In addition, inhibition of lipogenic enzymes and reduced expression of CD44 attenuated the activation of MET, Akt, FAK, and paxillin, which are known to regulate adhesion, migration and invasion. These changes were consistent with an observed decrease in migration and adhesion of CRC cells in functional assays and with re-organization of actin cytoskeleton upon FASN inhibition. Despite the modest effect of FASN inhibition on tumor growth in xenografts, attenuation of lipogenesis completely abolished establishment of hepatic metastasis and formation of secondary metastasis. Together, our findings suggest that targeting de novo lipogenesis may be a potential treatment strategy for advanced CRC.
\end{abstract}

\section{Keywords}

Fatty Acid Synthase (FASN); ATP-citrate lyase (ACLY); colorectal cancer (CRC); lipogenic enzymes

\section{INTRODUCTION}

Colorectal cancer (CRC) is the second leading cause of cancer-related deaths in the U.S. (1) The prognosis and life expectancy of patients with CRC are primarily determined by presence or absence of metastases, not by growth of the primary tumor (2). Treatment

Send correspondence to: B. Mark Evers, MD, Markey Cancer Center, University of Kentucky, 800 Rose Street, CC140, Lexington, KY 40536-0093, Telephone: (859) 323-6556, Fax: (859) 323-2074, mark.evers@uky.edu. 
options for metastatic CRC are limited and more selective therapeutic targets are needed to improve survival.

The signaling networks that determine progression of cancer to a metastatic phenotype include multiple alterations in the oncogenic pathways and significant changes in cellular metabolism. The fact that, in contrast to normal cells, the majority of fatty acids in malignant cells are derived from de novo lipogenesis regardless of the availability of extracellular lipids, suggests the importance of upregulation of endogenous lipid biosynthesis in malignant transformation (3). ATP-citrate lyase (ACLY) and fatty acid synthase (FASN), the key enzymes of de novo lipogenesis, are significantly upregulated in many cancers including CRC (3). Indeed, expression of FASN was increased in $86 \%$ of aberrant crypt foci (ACF) compared with that of adjacent normal colonic mucosa (4). Furthermore, metabolic profiling of CRC has shown an overall increase in the lipid content of polyps and tumors (5).

Neoplastic lipogenesis provides a selective proliferative and survival advantage and contributes to drug resistance in cancer cells (6-8). However, the impact of aberrant activation of lipogenic enzymes on metastases remains unknown. Expression of FASN is highest in metastatic tumors and correlates with decreased survival and disease recurrence in several tumor types $(9,10)$. Interestingly, proteomic characterization of CRC cell lines indicates that an increased expression of lipogenic enzymes is associated with a more aggressive metastatic phenotype (11). Furthermore, pharmacological inhibition of FASN provides indirect evidence of a possible connection between activation of lipogenesis and metastatic behavior of cancer cells (12-14).

Progression to a metastatic phenotype is associated with differential expression of proteins on the cell surface $(11,15)$. CD44, a transmembrane glycoprotein with multiple isoforms, is implicated in tumor progression and metastasis (16). Expression of CD44 is increased in CRC and correlates with poor clinical outcome $(17,18)$. The role of CD44 in metastases might be linked to its interaction with receptor tyrosine kinases such as c-MET, a protooncogene involved in tumor growth, invasion, and metastasis (19). Association of c-MET with CD44 isoforms at the plasma membrane appears to be essential for activation of cMET and downstream signaling in CRC (20).

In the present study, we determined the role of lipogenic enzymes in metastatic CRC. We demonstrate that in human tissue arrays, FASN is progressively increased with advancing stages of CRC. For the first time, this study establishes the link between expression of lipogenic enzymes and CD44. We show that inhibition of ACLY and FASN dramatically reduces expression of CD44 and attenuates CD44-associated signaling. We further demonstrate that suppressed expression of FASN decreases the tumorigenic and metastatic potential of CRC cells in vitro and in vivo. Collectively, our data suggest that upregulation of de novo lipogenesis is a critical step in CRC progression to metastases and that a better understanding of the link between metabolic changes in cancer cells and development of metastasis may lead to novel strategies to prevent and/or control advanced CRC.

\section{MATERIALS AND METHODS}

\section{Cell lines, lentiviral transduction, siRNA}

Human CRC lines KM20 and HCT116 were used as described previously and their identity was authenticated at the Johns Hopkins Genetic Resources Core Facility (Baltimore, MD) in October 2010, as previously reported (21). HT29 cells were purchased from ATCC

(Rockville, MD). For generation of stable knockdown KM20, HT29, and HCT116 cell lines, the lentiviral transduction particles containing shRNA for ACLY (SHCLNV-NM_001096), 
FASN (SHCLNV-NM_004104), or non-target shRNA (CHC002V) in pLKO.1-puro plasmid were purchased from Sigma (St. Louis, MO). Cells were transduced with virus in the presence of polybrene $(10 \mu \mathrm{g} / \mathrm{mL})$ for $24 \mathrm{~h}$ and then selected on puromycin $(10 \mu \mathrm{g} / \mathrm{mL})$. ON-TARGET plus CD44 siRNAs (LU-00999907, LU-00999908) and control siRNA (D-001810-10) were purchased from Dharmacon (Lafayette, CO) and used in a concentration of $100 \mu \mathrm{M}$.

\section{Antibodies}

Antibodies for Western blot and immunofluorescent staining were purchased from Cell Signaling (Danvers, MA): FASN (\#3180), ACLY (\#4332), pACLY (\#4331), CD44 (\#3570), pMET (\#3129), MET (\#3148), pSrc (\#2101), Src (\#2109), pAkt (\#4058L), Akt (\#4691L), ppaxillin (\#2541), paxillin (\#2542), pFAK (\#3283), FAK (\#3285), and RhoA (\#2117).

\section{Human tissue arrays}

The CO702 tissue array (US Biomax, USA), A203 (IV) tissue array (AccuMax, Japan), and FASN antibody (Cell Signaling, Danvers, MA) were purchased. Scoring was performed blindly by a pathologist according to a semiquantitative method (21). The extent score was assessed on a scale of $0-3$ (no positive cells $=0,<10 \%=1,10-50 \%=2$, positive staining of $>50 \%=3$ ); the intensity score was also measured on a scale of $0-3$ (negative $=0$, weak $=1$, moderate $=2$, strong $=3$ ). The immunoreactive score was obtained by summing these two scores.

\section{Analysis of de novo lipogenesis}

De novo palmitate synthesis was analyzed by stable isotope labeling. Cells were plated in normal growth medium. On Day 2, medium was replaced with medium containing sodium acetate (2-13C, 99\%, Cambridge Isotope Laboratories, Andover, MA) for $20 \mathrm{~h}$ at a concentration of $10 \mathrm{mM}$. Extraction of the lipids was performed as described previously (22) in the presence of an internal standard. Fatty acids were converted to 3-acyloxymethyl-1methylpyridinium iodide (AMPP) derivatives and the AMPP derivative of palmitic acid was quantified using a Shimadzu HPLC coupled to ABI 4000 Q-Trap hybrid linear ion trap triple quadrupole mass spectrometer operated in positive ESI mode as previously described (23). The instrument was operated in multiple reaction monitoring mode and the precursor product ion pairs monitored were 362.2/124.5 which represent the $[\mathrm{M}+\mathrm{H}]+$ mass of the AMPP derivative of palmitic acid and a fragment ion containing the N-pyridyl moiety. Enrichment of ${ }^{13} \mathrm{C}$ was determined from the ratio of integrated peak areas corresponding to the $\mathrm{mz} / 363.2 / 124.5$ and the $\mathrm{M}+1$ isotopomer $362.2 / 124.5$ precursor/product ion pairs.

\section{qRT- PCR}

Total RNA was isolated using an RNeasy mini kit (Qiagen, Valencia, CA). cDNA was synthesized using a high capacity cDNA reverse transcription kit (Applied Biosystems, Austin, TX). qRT-PCR was performed using a TaqMan Gene Expression Master Mix (\#4369016) according manufacture protocol and TaqMan probes for human CD44 (ID Hs1075862_m1) and human GAPDH (\# 4333764F) (Applied Biosystems, Austin, TX).

\section{Flow cytometry analysis and cell sorting}

Cells were labeled with $2 \mu \mathrm{g} / \mathrm{ml}$ CD44-FITC antibody (Abcam, Cambridge, MA) per $5 \times 10^{6}$ cells. For cell sorting, cells were washed and resuspended in Basic Sorting Buffer. For analysis of CD44 expression on cell surface, cells were resuspended in PBS, 10\% FCS, $1 \%$ sodium azide. Cell analysis and cell sorting were performed by the UK Flow Cytometry Service Facility. 


\section{Transwell migration assay}

A Boyden chamber migration assay with collagen-coated Transwells was performed with KM20 and HT29 cells for 20h as described previously (21). FBS $10 \%$ was used as a chemoattractant. Cells were counted in four different fields with an inverted microscope.

\section{Endothelial cell adhesion assay}

CRC cells were labeled with Calcein $\mathrm{AM}\left(2.5 \mu \mathrm{g} / \mathrm{mL}\right.$ final concentration) at $37^{\circ} \mathrm{C}$, added atop a monolayer of human microvascular endothelial cells from lungs (HMVEC-L) for 30 min. Prior to the experiment, HMVEC-L cells were activated with $10 \mathrm{ng} / \mathrm{mL}$ of TGFa for 4h. Unattached cells were removed by washing with PBS (5x). Three images per well were taken to count attached cells.

\section{In vivo studies}

Male athymic nude ${ }^{\text {nu/nu }}$ mice (5-6 weeks old) (Charles River Laboratories, Wilmington, MA) were housed in the Markey Cancer Center Small Animal Facility. All procedures were performed using protocols approved by the UK Animal Care and Use Committee. To establish CRC xenografts, mice were injected with $1 \times 10^{6}$ cells/100 $\mu$ of KM20 or HT29 with non-targeting control (NTC) shRNA and FASN shRNA (5 mice/group). To assess establishment of hepatic metastasis, HT29-GFP-Luc cells $\left(2 \times 10^{6}\right.$ cells/100 $\left.\mu 1\right)$ were injected intrasplenically as previously described (24). For experimental metastasis models, control and stable knockdown HT29-GFP-Luc cells or KM20-GFP-Luc $\left(2 \times 10^{6}\right.$ cells/300 $\mu$ l) were injected into the tail vein of athymic nude mice ( $n=4$ and $n=5$ per group, respectively). To monitor metastasis, mice were anesthetized with isoflurane, given a single i.p. dose of $150 \mathrm{mg} / \mathrm{kg}$ D-luciferin in PBS and imaged 8 min after injection (IVIS Spectrum, Caliper Sciences). Results were analyzed using Living Image 3.0 software.

\section{Statistical methods}

ANOVA with test for linear trend and pairwise comparisons was performed to compare immunoreactivity scores in normal mucosa and CRC of various stages. ANOVA was also employed for multiple group comparison of shRNA (ACLY and FASN) with NTC for CD44 levels while two-sample t-test or Wilcoxon rank sum test was used for two group comparisons of migration, number of colonies and tumor weight between FASN vs. NTC. Comparison of log values of tumor volume measured over time was performed using a linear mixed model. Analyses were performed separately for each cell line.

\section{RESULTS}

\section{FASN is highly expressed in primary CRCs and liver metastases}

Evaluations of FASN in human ACF and primary CRCs have revealed elevated expression of this enzyme in early stages of colorectal tumorigenesis as compared to normal mucosa (4, 25-27). To extend these studies, we analyzed expression of FASN in CRC clinical samples by immunohistochemistry (Fig. 1A). Expression of FASN was detected in the cytoplasm in all stages of primary CRC, though some variability was observed within different regions of individual tumor cores. Statistical evaluation of immunoreactivity scores demonstrated increased expression of FASN in Stages II-IV CRC as compared to normal mucosa. Analysis of primary tumors, matched liver metastases and normal colonic mucosa from Stage IV patients demonstrated significantly higher expression of FASN in both the primary CRC and liver metastasis as compared to normal colon mucosa (Supplementary Fig. 1).

We also tested expression of ACLY and FASN in a panel of CRC cell lines. Consistent with results obtained from human tissue arrays, Western blot analysis demonstrated high 
expression/activation of lipogenic enzymes (Fig. 1B). These data suggest that enhanced de novo lipid biosynthesis may play a role in progression of primary CRC to metastatic disease.

\section{Inhibition of lipogenic enzymes decreases expression of CD44}

CD44 and c-Met have been implicated in CRC metastasis via regulation of tumor cell growth, adhesion, migration and invasion $(16,28,29)$. Considering that tumor-produced fatty acids preferentially partition into lipid rafts (30), we hypothesized that altered expression of lipogenic enzymes may affect CD44 and c-Met since their functions have been attributed to these rafts $(31,32)$. First, we analyzed expression of CD44 and c-Met in a panel of CRC cell lines. CD44 variant isoforms (CD44v), which are primarily implicated in regulation of metastasis, are highly expressed in most cell lines (Fig. 2A). In contrast with other cell lines, the non-metastatic SW480 cell line expresses a low level of CD44v and a high level of CD44 standard isoform (CD44s). Activation of c-Met was observed in KM20, HT29, and HCT116 cell lines, and we used these three cell lines to establish a stable shRNA-mediated knockdown of either ACLY or FASN to investigate the role of de novo lipogenesis in metastatic CRC.

To confirm inhibition of lipid biosynthesis when ACLY and FASN are inhibited, cells were exposed to stable isotope-labeled acetate and its incorporation into palmitate was measured by mass spectrometry. Targeted inhibition of ACLY and FASN led to a $60-100 \%$ decrease in de novo palmitate synthesis (Fig. 2B). Interestingly, reduced expression of ACLY and FASN was also associated with changes in cellular morphology (Supplementary Fig. 2). We demonstrate that inhibition of ACLY and FASN significantly decreases expression of the CD44 protein. A more pronounced inhibition of CD44 was observed in cells with knockdown of FASN compared with that of ACLY (Fig. 2C). Treatment of HT29 cells with C-75, a synthetic inhibitor of enzymatic activity of FASN, also led to a dose-dependent decrease in expression of CD44 (Fig. 2D). Interestingly, upregulation of FASN expression by transient transfection of myristoylated, constitutively active form of Akt1 (myr-Akt1) or Akt2 (myr-Akt2) had an opposite effect and increased expression of CD44 in HT29 cells (Fig. 2E).

To further evaluate the correlation of CD44 expression and FASN, we performed direct labeling of FASN knockdown HT29 cells with the CD44-FITC antibody. These cells were cultured for 3 weeks prior to the experiment and demonstrated a mixed population of cells with differential expression of FASN as confirmed by immunofluorescent staining (data not shown). CD44-FITC labeled cells were sorted based on the level of CD44 expression. Cells with low expression of CD44 demonstrated concomitant reduction of FASN expression (Fig. 2F).

To elucidate the mechanism for the downregulation of CD44 in ACLY and FASN knockdown cells, we assessed the level of CD44 mRNA in KM20, HT29, and HCT116 cell lines each with stable knockdown of either ACLY or FASN. We observed a slight decrease in CD44 mRNA in HCT116 and KM20, but not in the HT29 cell line (Fig. 2G). It has been previously shown that expression of CD44 can be regulated by posttranscriptional modifications such as palmitoylation (32). To test the possible involvement of this mechanism in the regulation of CD44 expression in CRC cells, we used 2-Bromopalmitate (2-BP), a non-metabolizable palmitate analog, to block the incorporation of palmitate into proteins. HT29 NTC and FASN knockdown cells were treated with either DMSO or $200 \mu \mathrm{M}$ of 2-BP, labeled with CD44-FITC antibody, and analyzed by flow cytometry. The analysis demonstrated a 2-fold decrease in signal intensity on the cell surface in FASN knockdown and 2-BP treated cells versus control HT29 cells (Supplementary Fig. 3A). Consistent with these data, subcellular fractionation revealed that expression of CD44 in the membrane fraction is significantly lower in FASN knockdown and 2-BP treated cells compared with 
control HT29 cells (Supplementary Fig. 3B). Together, these data suggest that de novo lipogenesis regulates expression of CD44 at a post-transcriptional level, possibly by altering its palmitoylation.

\section{Inhibition of lipogenic enzymes attenuates c-Met signaling in CRC cells}

Recent studies have shown a functional link between expression of FASN and activation of c-Met (33). To test whether a decrease in expression of lipogenic enzymes affects activity of c-Met in CRC, we first analyzed the expression and activation of c-Met in KM20 and HT29 with stable knockdown of ACLY and FASN. As shown in Fig. 3A, phosphorylation of Tyr $1234 / 1235$ in the c-Met kinase domain is inhibited by knockdown of FASN in KM20 cells and by knockdown of both ACLY and FASN in HT29 cells.

To further confirm that attenuation of c-Met signaling is due to inhibition of lipogenic enzymes, we serum-starved HT29 and KM20 cells (control, ACLY and FASN knockdown) for $24 \mathrm{~h}$ and then treated them with $10 \mathrm{ng} / \mathrm{ml}$ of hepatocyte growth factor (HGF), a c-Met receptor ligand, for $20 \mathrm{~min}$. Consistent with data from the previous experiment, activation of c-Met by HGF was prevented by knockdown of FASN in both KM20 and HT29 cell lines (Fig. 3B).

To test whether changes in activity of c-MET are CD44-dependent, KM20 and HT29 cells were transiently transfected with two different CD44 siRNAs or control siRNA. As shown in Fig. 3C, inhibition of CD44 decreases c-MET activity in HT29, but not in KM20 cells.

Together, these findings suggest that upregulation of lipogenesis during cancer progression regulates c-Met signaling.

\section{Expression of FASN regulates CRC cell growth, adhesion, and migration}

An important pro-metastatic characteristic of cancer cells is their ability to grow in an anchorage-independent manner. KM20 and HT29 cells (control and FASN knockdown) were tested for their ability to grow without attaching to a substrate using soft agar assay. In both cell lines we observed a significant decrease in the number of colonies formed when expression of FASN was inhibited (Fig. 4A).

Tumor cell intravasation and extravasation are important steps in metastasis and require cancer cells to interact and adhere to endothelial cells. In CRC, CD44 is implicated in regulation of adherence of cancer cells to endothelial cells and their subsequent transendothelial migration (34). To test whether inhibition of FASN can affect the ability of CRC cells to attach to endothelial cells, we used control and FASN knockdown KM20 and HT29 cells labeled with Calcein AM. Cells were added atop a monolayer of HMVEC-L preactivated with TGFa, and incubated for $30 \mathrm{~min}$. Unattached cells were removed by multiple washes. Data demonstrated that downregulation of FASN in KM20 and HT29 cells impairs their ability to attach to endothelial cells (Fig. 4B).

Enhanced cell migration is associated with a metastatic phenotype. The results from the Transwell migration assay demonstrated that inhibition of FASN impairs migration in both KM20 and HT29 cell lines (Fig. 4C). Collectively, these findings suggest that de novo lipogenesis plays a significant functional role in progression of CRC.

\section{Inhibition of lipogenic enzymes alters the signaling network that regulates adhesion and motility in CRC}

The cooperation between CD44 and c-Met at the plasma membrane and their dynamic interactions with multiple downstream molecules leads to activation of the signaling 
network that regulates cell growth, adhesion, and migration (16). Activation of tyrosine kinase Src by c-Met contributes to the metastatic potential of CRC cells via regulation of the actin cytoskeleton and modulation of the formation of adhesive structures (35). Furthermore, expression of CD44 and activation of c-MET promote phosphorylation of focal adhesion kinase (FAK) and promote cell motility (36). Interestingly, cooperation of Src and FAK kinases leads to phosphorylation of paxillin and also contributes to stimulation of cell motility (37) (Fig. 5A). Our data demonstrates that inhibition of expression of ACLY and FASN in KM20 and HT29 decreases phosphorylation of Src (Fig. 5B). Since phosphorylation of Src is associated with downstream activation of FAK and paxillin, we examined expression of these proteins in HT29 and KM20 with stable knockdown of either ACLY or FASN. Phosphorylation of paxillin on Tyr 118 was inhibited only by knockdown of FASN in both KM20 and HT29 cell lines (Fig. 5C). Interestingly, the effect of FASN knockdown on phosphorylation of FAK was more prominent than the effect of ACLY knockdown (Fig. 5C). Consistent with several studies showing the connection between upregulation of lipogenesis and activation of Akt $(7,8)$, we observed a decrease in phosphorylation of Akt in both KM20 and HT29 cell lines with stable knockdown of either ACLY or FASN (Fig. 5D). Furthermore, CD44-dependent expression of RhoA induces formation of stress fibers and is required for focal adhesion formation (38). Our data demonstrate a significant decrease in expression of RhoA in ACLY and FASN knockdown KM20 and HT29 cell lines (Fig. 5D).

To test whether these changes are CD44-dependent, KM20 and HT29 cells were transiently transfected with CD44 siRNAs or control siRNA and expression/activity of aforementioned proteins were assessed. As shown in Fig. 5E, inhibition of CD44 significantly decreases expression of RhoA and activity of Akt in both cell lines. Interestingly, knockdown of CD44 decreased activity of Src and FAK only in HT29 cells and did not affect activity of paxillin in either cell line (Fig. 5E).

Actin cytoskeleton plays an important role in regulation of cell growth, adhesion, motility and invasion. Considering that activation of CD44/c-Met and Src affects cell motility by regulating actin polymerization, depolymerization, and stress fiber formation, we performed immunofluorescence staining for F-actin. Phalloidin staining demonstrated significant changes in organization of actin cytoskeleton in cells with FASN knockdown compared to control cells (Fig. 5E). Furthermore, in agreement with Western blot analysis, immunofluorescent staining of control and FASN knockdown cells for phospho-FAK and phospho-paxillin demonstrated a significant decrease in number of focal adhesions in FASN knockdown KM20 and HT29 cells. Our findings suggest that inhibition of lipogenesis in CRC cells induces molecular changes and re-organization of actin cytoskeleton, which are consistent with a less motile and invasive phenotype of cancer cells.

\section{Inhibition of FASN decreases tumor growth and attenuates CRC liver metastasis}

It has been previously demonstrated that CRC xenografts treated with C-75 exhibit inhibition of tumor growth (7). To test whether molecular inhibition of FASN expression affects tumor growth in vivo, we injected control or FASN knockdown cells subcutaneously into athymic nude mice. Tumor growth was monitored by measurement of tumor volume (Fig. 6A). Mice were sacrificed at day 27 after the inoculation and tumor weight was recorded (Fig. 6B). We observed a slower rate of tumor growth and smaller tumor size in the FASN-treated mice versus control ( $\mathrm{p}=0.002$ for KM20; $\mathrm{p}=\mathrm{NS}$ for HT29). Expression of FASN and CD44 in tumors from control and FASN knockdown groups was assessed by Western blot and showed partial recovery of expression of both proteins at the end of the experiment (Fig. 6C). 
The liver is the most common site for CRC metastasis and intrasplenic injections recapitulate the process of liver metastasis. We injected green fluorescent protein (GFP)labeled control or FASN knockdown HT29 cells into the spleens of athymic nude mice and assessed the presence of liver metastasis by GFP imaging and immunohistochemical analysis at 6 weeks after injection. Primary tumors were observed in $100 \%$ of mice in the control group versus $40 \%$ of mice in the FASN knockdown group (Fig. 6D). Liver metastases were observed in $80 \%$ of the mice injected with control HT29 cells, while complete absence of liver metastasis was observed in mice injected with FASN knockdown cells (Fig. 6D-E). Presence or absence of liver metastasis was confirmed by H\&E staining (Fig. 6F). Data from these experiments provide support for the role of lipogenesis in tumor growth and potentially in the metastasis of CRC.

\section{Inhibition of FASN attenuates establishment of CRC metastasis}

To further investigate the role de novo lipogenesis plays in metastasis, we examined the effect of FASN inhibition in an experimental metastasis model in vivo. Luciferase and GFPlabeled HT29 and KM20 cells with stable knockdown of FASN were injected intravenously (i.v.) into athymic nude mice and formation of systemic metastasis was assessed by bioluminescent and fluorescent imaging. All mice in the HT29 control group demonstrated metastatic nodules (Fig. 7A). The distribution of values for total luciferase signal per animal is shown in Fig. 7B. Luciferase signal was associated with metastatic nodules on the backs of the animals and metastasis to the mesenteric lymph nodes. In contrast, none of the metastatic nodules were formed in the HT29 FASN knockdown group. However, histological examination of lungs showed the presence of pulmonary micrometastasis in both the control and FASN knockdown groups (Fig. 7C).

Similar results were obtained when we used another metastatic CRC cell line, KM20. Systemic metastases were noted in $80 \%$ of mice from the control group; however, knockdown of FASN completely abolished establishment of metastasis as depicted by luciferase imaging and quantification of total luciferase signal per mouse (Fig. 7D and E). Surprisingly, in contrast to HT29 inoculated mice, histological examination showed the presence of pulmonary micrometastasis in $60 \%$ of mice in the KM20 control group and complete absence of micrometastasis in the group injected with FASN knockdown KM20 cells (Fig. 7 F). The presence of pulmonary metastasis in the control group was also visualized using GFP imaging (Supplementary Fig.4). Taken together, these findings suggest that overexpression of FASN may play an important role in establishment of CRC metastasis in vivo.

\section{DISCUSSION}

In present study, we investigated the role of de novo lipogenesis in CRC metastases. Although, multiple studies have focused on the contribution of aberrant expression of lipogenic enzymes to growth and survival of cancer cells, their role in metastasis remains unknown $(39,40)$. Here, we demonstrate an increase in expression of FASN with advancing stages of CRC, suggesting that FASN may play an important role in the progression of CRC to metastatic disease. Furthermore, this study demonstrates that inhibition of lipogenic enzymes decreases expression of CD44 and attenuates the CD44-associated signaling, thus establishing the novel link between lipid biosynthesis and metastasis. Finally, we show that targeted inhibition of FASN decreases the tumorigenic potential of CRC cells in vitro and attenuates establishment of metastasis in two experimental metastasis models in vivo.

Increased expression of CD44 correlates with metastasis in many cancers (16). We showed that changes in CD44 in CRC cells with inhibited expression of lipogenic enzymes are not due to transcriptional regulation, but possibly to post-transcriptional modifications of 
protein. CD44 undergoes a sequential proteolytic cleavage and releases CD44 intracellular domain, which acts as a transcriptional factor and regulates expression of its own gene (36). This mechanism can explain a slight decrease in CD44 mRNA noted in KM20 and HCT116 cells when lipogenic enzymes are inhibited. Expression of CD44 is dramatically higher in HT29 cells, so it is possible that CD44 is not dependent on self-regulation.

c-Met is implicated in promotion of metastasis (19). Consistent with studies of diffuse large B-cell lymphoma and prostate cancer, demonstrating the link between inhibition of FASN and decreased phosphorylation of c-Met $(33,41)$, our data show that inhibition of lipogenic enzymes decreases endogenous activation of c-Met and prevents its activation by HGF in CRC cells. Interestingly, CD44 is required for c-Met activation and signaling in several cancers $(20,42)$. Consistently, we demonstrated that decreased phosphorylation of c-Met in FASN-depleted cells is CD44-dependent in HT29 cells. The differential effect of CD44 inhibition on c-Met activity in KM20 and HT29 cells can be explained by a significantly higher level of CD44 expression and c-MET activation in HT29 cells.

Overexpression of FASN in breast cancer cells increased the size and number of colonies in soft agar (43). In agreement with this study, we demonstrate that inhibition of FASN leads to a significant decrease in the ability of CRC cells to grow in an anchorage-independent manner. Additionally, we show that altered lipogenesis regulates attachment of CRC cells to endothelial cells. Suppressed migration is associated with reduced activity of FASN in ovarian carcinoma cells (14). Consistently, we also observed a significant decrease in migration of both KM20 and HT29 cell lines when expression of FASN is inhibited. Considering that suppression of lipogenic enzymes inhibits expression of CD44 and decreases activation of c-Met, these functional changes can be explained by alterations in the signaling network downstream of these two proteins. Our data show that KM20 and HT29 cells, with inhibited expression of FASN, exhibit significant suppression of Src, FAK, and paxillin activation, the proteins which are downstream of the CD44/c-Met complex and implicated in regulation of adhesion dynamics, migration, and invasion of cancer cells (44). Indeed, the level of FAK receptors and their phosphorylation has been shown to increase during the adenoma to carcinoma transition of colonic epithelia (45). Furthermore, activation of Src contributes to anoikis resistance in CRC cells through activation of phosphatidylinositol 3-kinase (PI3K)/Akt pathway and phosphorylation of Akt (46). Additionally, overexpression of FASN has been associated with activation of Akt in human CRC tissue samples (7). Consistent with these findings, we also observed a CD44-dependent decrease in activation of Akt in HT29 and KM20 cells with inhibited expression of lipogenic enzymes. Interestingly, inhibition of CD44 attenuates activation of Src and FAK in HT29, but not in the KM20 cell line, suggesting that the effect of inhibition of lipogenic enzymes on downstream signaling may be mediated by altered composition of lipid rafts within the plasma membrane and impairment of activation/function of membrane-associated receptors or oncoproteins other than CD44 and c-MET (47).

Inhibition of lipogenic enzymes decreases cell growth in several types of cancers (40). Furthermore, FASN inhibition with C-75 slows growth of CRC xenografts (7). Our findings are consistent with these studies and demonstrate that inhibition of lipogenesis attenuates the rate of tumor growth and decreases tumor size in both KM20 and HT29 xenografts. Interestingly, we observed the partial recovery of FASN expression and a subsequent increase in expression of CD44 in xenografts, supporting the importance of lipogenesis for cancer cell survival and growth.

Implantation of cancer cells into the spleens of nude mice results in primary tumor growth and establishment of hepatic metastases (24). The liver metastasis model primarily evaluates late stages of metastasis and recapitulates the pattern of colorectal metastasis in humans 
(24). Using this model, we demonstrated that despite detection of primary tumors in both control and FASN knockdown groups, inhibition of FASN prevented formation of liver metastasis. Furthermore, results from the experimental metastasis model, carried out with both KM20 and HT29 cell lines, demonstrated that inhibition of FASN expression blocked establishment of metastatic nodules in nude mice. The control mice developed multiple metastatic nodules, predominantly located on the upper back and mesenteric lymph nodes. This pattern of tumor formation is similar to what was reported in a previous publication by our laboratory (21). Surprisingly, gross examination of the lungs showed a different effect of the downregulation of FASN on establishment of microscopic nodules. Knockdown of FASN in KM20 cells prevented formation of micrometastasis in the lungs; however, its inhibition in the HT29 cells did not affect formation of tumor nodules. This discrepancy can likely be explained by the different genetic backgrounds of HT29 and KM20 cell lines. It is possible that downregulation of FASN has different consequences on modulation of signaling pathways and metastatic potential in these cell lines. Furthermore, in the experimental metastasis model, colonization of cells in the lungs does not recapitulate all steps of the metastatic cascade, and formation of secondary metastatic lesions, which were depicted by the bioluminescent imaging in our experiment, provides a better model for evaluation of the metastatic potential of cancer cells. Taken together, data from our in vivo experiments suggest that downregulation of lipogenesis in cancer cells has a more prominent effect on metastasis than on the growth of primary tumors.

Due to the strong correlation between de novo lipid biosynthesis and the malignant phenotype, lipogenic enzymes have become an attractive target for therapeutic intervention. In particular, FASN, due to its structure and tumor-specific expression, represents a unique target for cancer drug discovery (48). Despite, multiple publications clearly demonstrating the role of FASN in cancer cell growth and survival, our study is the first to provide insight into the contribution of aberrant de novo lipogenesis progression and metastasis of CRC suggesting that inhibition of FASN may be a potential therapeutic strategy for advanced stages of CRC. We also demonstrate the link between expression of lipogenic enzymes and expression of $\mathrm{CD} 44$, the protein implicated in establishing of metastasis in many cancers including CRC. Humanized CD44 antibodies have shown promising results in clinical trials, but those trials were terminated due to skin-related toxicities $(49,50)$. The findings presented in this study open the possibility of targeting CD44 through inhibition of lipogenesis, thus avoiding antibody-associated toxicities.

\section{Supplementary Material}

Refer to Web version on PubMed Central for supplementary material.

\section{Acknowledgments}

The authors thank Donna Gilbreath, Jennifer Rogers, and Nathan Vanderford, Ph.D. for help with manuscript preparation and Greg Bauman and Jennifer Strange for assistance with FACS.

\section{GRANT SUPPORT}

This work was supported by P20CA1530343 (GI SPORE; B.M. Evers), GM50388 and P20RR021954 (A.J. Morris).

\section{REFERENCES}

1. Jemal A, Bray F, Center MM, Ferlay J, Ward E, Forman D. Global cancer statistics. CA Cancer J Clin. 2011; 61:69-90. [PubMed: 21296855]

2. Mina LA, Sledge GW Jr. Rethinking the metastatic cascade as a therapeutic target. Nat Rev Clin Oncol. 2011; 8:325-332. [PubMed: 21502993] 
3. Furuta E, Okuda H, Kobayashi A, Watabe K. Metabolic genes in cancer: Their roles in tumor progression and clinical implications. Biochim Biophys Acta. 2010

4. Kearney KE, Pretlow TG, Pretlow TP. Increased expression of fatty acid synthase in human aberrant crypt foci: possible target for colorectal cancer prevention. Int J Cancer. 2009; 125:249_ 252. [PubMed: 19358283]

5. Ong ES, Zou L, Li S, Cheah PY, Eu KW, Ong CN. Metabolic profiling in colorectal cancer reveals signature metabolic shifts during tumorigenesis. Mol Cell Proteomics. 2010

6. Mashima T, Seimiya H, Tsuruo T. De novo fatty-acid synthesis and related pathways as molecular targets for cancer therapy. Br J Cancer. 2009; 100:1369-1372. [PubMed: 19352381]

7. Uddin S, Hussain AR, Ahmed M, Abubaker J, Al-Sanea N, Abduljabbar A, et al. High prevalence of fatty acid synthase expression in colorectal cancers in Middle Eastern patients and its potential role as a therapeutic target. Am J Gastroenterol. 2009; 104:1790-1801. [PubMed: 19491830]

8. Uddin S, Jehan Z, Ahmed M, Alyan A, Al-Dayel F, Hussain A, et al. Over Expression of Fatty Acid Synthase in Middle Eastern Epithelial Ovarian Carcinoma Activates AKT and its Inhibition Potentiates Cisplatin Induced Apoptosis. Mol Med. 2011

9. Alo PL, Visca P, Marci A, Mangoni A, Botti C, Di Tondo U. Expression of fatty acid synthase (FAS) as a predictor of recurrence in stage I breast carcinoma patients. Cancer. 1996; 77:474-482. [PubMed: 8630954]

10. Camassei FD, Cozza R, Acquaviva A, Jenkner A, Rava L, Gareri R, et al. Expression of the lipogenic enzyme fatty acid synthase (FAS) in retinoblastoma and its correlation with tumor aggressiveness. Invest Ophthalmol Vis Sci. 2003; 44:2399-2403. [PubMed: 12766036]

11. Luque-Garcia JL, Martinez-Torrecuadrada JL, Epifano C, Canamero M, Babel I, Casal JI. Differential protein expression on the cell surface of colorectal cancer cells associated to tumor metastasis. Proteomics. 2010; 10:940-952. [PubMed: 20049862]

12. Murata S, Yanagisawa K, Fukunaga K, Oda T, Kobayashi A, Sasaki R, et al. Fatty acid synthase inhibitor cerulenin suppresses liver metastasis of colon cancer in mice. Cancer Sci. 2010; 101:1861-1865. [PubMed: 20491775]

13. Carvalho MA, Zecchin KG, Seguin F, Bastos DC, Agostini M, Rangel AL, et al. Fatty acid synthase inhibition with Orlistat promotes apoptosis and reduces cell growth and lymph node metastasis in a mouse melanoma model. Int J Cancer. 2008; 123:2557-2565. [PubMed: 18770866]

14. Selvendiran K, Ahmed S, Dayton A, Ravi Y, Kuppusamy ML, Bratasz A, et al. HO-3867, a synthetic compound, inhibits the migration and invasion of ovarian carcinoma cells through downregulation of fatty acid synthase and focal adhesion kinase. Mol Cancer Res. 2010; 8:11881197. [PubMed: 20713491]

15. Rambaruth ND, Dwek MV. Cell surface glycan-lectin interactions in tumor metastasis. Acta Histochem. 2011; 113:591-600. [PubMed: 21501858]

16. Orian-Rousseau V. CD44, a therapeutic target for metastasising tumours. Eur J Cancer. 2010; 46:1271-1277. [PubMed: 20303742]

17. Wielenga VJ, van der Neut R, Offerhaus GJ, Pals ST. CD44 glycoproteins in colorectal cancer: expression, function, and prognostic value. Adv Cancer Res. 2000; 77:169-187. [PubMed: 10549358]

18. Kopp R, Fichter M, Schalhorn G, Danescu J, Classen S. Frequent expression of the high molecular, 673-bp CD44v3,v8-10 variant in colorectal adenomas and carcinomas. Int J Mol Med. 2009; 24:677-683. [PubMed: 19787202]

19. Trusolino L, Bertotti A, Comoglio PM. MET signalling: principles and functions in development, organ regeneration and cancer. Nat Rev Mol Cell Biol. 2010; 11:834-848. [PubMed: 21102609]

20. Orian-Rousseau V, Chen L, Sleeman JP, Herrlich P, Ponta H. CD44 is required for two consecutive steps in HGF/c-Met signaling. Genes Dev. 2002; 16:3074-3086. [PubMed: 12464636]

21. Gulhati P, Bowen KA, Liu J, Stevens PD, Rychahou PG, Chen M, et al. mTORC1 and mTORC2 Regulate EMT, Motility, and Metastasis of Colorectal Cancer via RhoA and Rac1 Signaling Pathways. Cancer Res. 2011; 71:3246-3256. [PubMed: 21430067]

22. Bligh EG, Dyer WJ. A rapid method of total lipid extraction and purification. Can J Biochem Physiol. 1959; 37:911-917. [PubMed: 13671378] 
23. Yang WC, Adamec J, Regnier FE. Enhancement of the LC/MS analysis of fatty acids through derivatization and stable isotope coding. Anal Chem. 2007; 79:5150-5157. [PubMed: 17492837]

24. Rychahou PG, Kang J, Gulhati P, Doan HQ, Chen LA, Xiao SY, et al. Akt2 overexpression plays a critical role in the establishment of colorectal cancer metastasis. Proc Natl Acad Sci U S A. 2008; 105:20315-20320. [PubMed: 19075230]

25. Notarnicola M, Altomare DF, Calvani M, Orlando A, Bifulco M, D'Attoma B, et al. Fatty acid synthase hyperactivation in human colorectal cancer: relationship with tumor side and sex. Oncology. 2006; 71:327-332. [PubMed: 17687193]

26. Ogino S, Nosho K, Meyerhardt JA, Kirkner GJ, Chan AT, Kawasaki T, et al. Cohort study of fatty acid synthase expression and patient survival in colon cancer. J Clin Oncol. 2008; 26:5713-5720. [PubMed: 18955444]

27. Rashid A, Pizer ES, Moga M, Milgraum LZ, Zahurak M, Pasternack GR, et al. Elevated expression of fatty acid synthase and fatty acid synthetic activity in colorectal neoplasia. Am J Pathol. 1997; 150:201-208. [PubMed: 9006336]

28. Gunthert U, Hofmann M, Rudy W, Reber S, Zoller M, Haussmann I, et al. A new variant of glycoprotein CD44 confers metastatic potential to rat carcinoma cells. Cell. 1991; 65:13-24. [PubMed: 1707342]

29. Holgren C, Dougherty U, Edwin F, Cerasi D, Taylor I, Fichera A, et al. Sprouty-2 controls c-Met expression and metastatic potential of colon cancer cells: sprouty/c-Met upregulation in human colonic adenocarcinomas. Oncogene. 2010; 29:5241-5253. [PubMed: 20661223]

30. Swinnen JV, Van Veldhoven PP, Timmermans L, De Schrijver E, Brusselmans K, Vanderhoydonc F, et al. Fatty acid synthase drives the synthesis of phospholipids partitioning into detergentresistant membrane microdomains. Biochem Biophys Res Commun. 2003; 302:898-903. [PubMed: 12646257]

31. Wang L, Zhao YF, Li YL, Xu YF, Xia Q, Ma KL. Effects of lipid rafts on signal transmembrane transduction mediated by c-Met. Zhonghua Gan Zang Bing Za Zhi. 2008; 16:449-452. [PubMed: 18578997]

32. Thankamony SP, Knudson W. Acylation of CD44 and its association with lipid rafts are required for receptor and hyaluronan endocytosis. J Biol Chem. 2006; 281:34601-34609. [PubMed: 16945930]

33. Uddin S, Hussain AR, Ahmed M, Bu R, Ahmed SO, Ajarim D, et al. Inhibition of fatty acid synthase suppresses c-Met receptor kinase and induces apoptosis in diffuse large B-cell lymphoma. Mol Cancer Ther. 2010; 9:1244-1255. [PubMed: 20423996]

34. Fujisaki T, Tanaka Y, Fujii K, Mine S, Saito K, Yamada S, et al. CD44 stimulation induces integrin-mediated adhesion of colon cancer cell lines to endothelial cells by up-regulation of integrins and c-Met and activation of integrins. Cancer Res. 1999; 59:4427-4434. [PubMed: 10485493]

35. Herynk MH, Zhang J, Parikh NU, Gallick GE. Activation of Src by c-Met overexpression mediates metastatic properties of colorectal carcinoma cells. J Exp Ther Oncol. 2007; 6:205-217. [PubMed: 17552361]

36. Zoller M. CD44: can a cancer-initiating cell profit from an abundantly expressed molecule? Nat Rev Cancer. 2011; 11:254-267. [PubMed: 21390059]

37. Brown MC, Cary LA, Jamieson JS, Cooper JA, Turner CE. Src and FAK kinases cooperate to phosphorylate paxillin kinase linker, stimulate its focal adhesion localization, and regulate cell spreading and protrusiveness. Mol Biol Cell. 2005; 16:4316-4328. [PubMed: 16000375]

38. Bourguignon LY, Wong G, Earle C, Krueger K, Spevak CC. Hyaluronan-CD44 interaction promotes c-Src-mediated twist signaling, microRNA-10b expression, and RhoA/RhoC upregulation, leading to Rho-kinase-associated cytoskeleton activation and breast tumor cell invasion. J Biol Chem. 2010; 285:36721-36735. [PubMed: 20843787]

39. Menendez JA, Lupu R. Fatty acid synthase and the lipogenic phenotype in cancer pathogenesis. Nat Rev Cancer. 2007; 7:763-777. [PubMed: 17882277]

40. Kuhajda FP. Fatty-acid synthase and human cancer: new perspectives on its role in tumor biology. Nutrition. 2000; 16:202-208. [PubMed: 10705076] 
41. Coleman DT, Bigelow R, Cardelli JA. Inhibition of fatty acid synthase by luteolin posttranscriptionally down-regulates c-Met expression independent of proteosomal/lysosomal degradation. Mol Cancer Ther. 2009; 8:214-224. [PubMed: 19139131]

42. Suzuki M, Kobayashi H, Kanayama N, Nishida T, Takigawa M, Terao T. CD44 stimulation by fragmented hyaluronic acid induces upregulation and tyrosine phosphorylation of c-Met receptor protein in human chondrosarcoma cells. Biochim Biophys Acta. 2002; 1591:37-44. [PubMed: 12183053]

43. Vazquez-Martin A, Colomer R, Brunet J, Lupu R, Menendez JA. Overexpression of fatty acid synthase gene activates HER1/HER2 tyrosine kinase receptors in human breast epithelial cells. Cell Prolif. 2008; 41:59-85. [PubMed: 18211286]

44. Lawrence RE, Salgia R. MET molecular mechanisms and therapies in lung cancer. Cell Adh Migr. 2010; 4:146-152. [PubMed: 20139696]

45. Brunton VG, Ozanne BW, Paraskeva C, Frame MC. A role for epidermal growth factor receptor, c-Src and focal adhesion kinase in an in vitro model for the progression of colon cancer. Oncogene. 1997; 14:283-293. [PubMed: 9018114]

46. Windham TC, Parikh NU, Siwak DR, Summy JM, McConkey DJ, Kraker AJ, et al. Src activation regulates anoikis in human colon tumor cell lines. Oncogene. 2002; 21:7797-7807. [PubMed: 12420216]

47. Menendez JA, Vellon L, Lupu R. Targeting fatty acid synthase-driven lipid rafts: a novel strategy to overcome trastuzumab resistance in breast cancer cells. Medical Hypotheses. 2005; 64:9971001. [PubMed: 15780499]

48. Kridel SJ, Lowther WT, Pemble CWt. Fatty acid synthase inhibitors: new directions for oncology. Expert Opin Investig Drugs. 2007; 16:1817-1829.

49. Koppe M, Schaijk F, Roos J, Leeuwen P, Heider KH, Kuthan H, et al. Safety, pharmacokinetics, immunogenicity, and biodistribution of (186) Re-labeled humanized monoclonal antibody BIWA 4 (Bivatuzumab) in patients with early-stage breast cancer. Cancer Biother Radiopharm. 2004; 19:720-729. [PubMed: 15665619]

50. Riechelmann H, Sauter A, Golze W, Hanft G, Schroen C, Hoermann K, et al. Phase I trial with the CD44v6-targeting immunoconjugate bivatuzumab mertansine in head and neck squamous cell carcinoma. Oral Oncol. 2008; 44:823-829. [PubMed: 18203652] 


\section{A}

\section{Primary CRC}
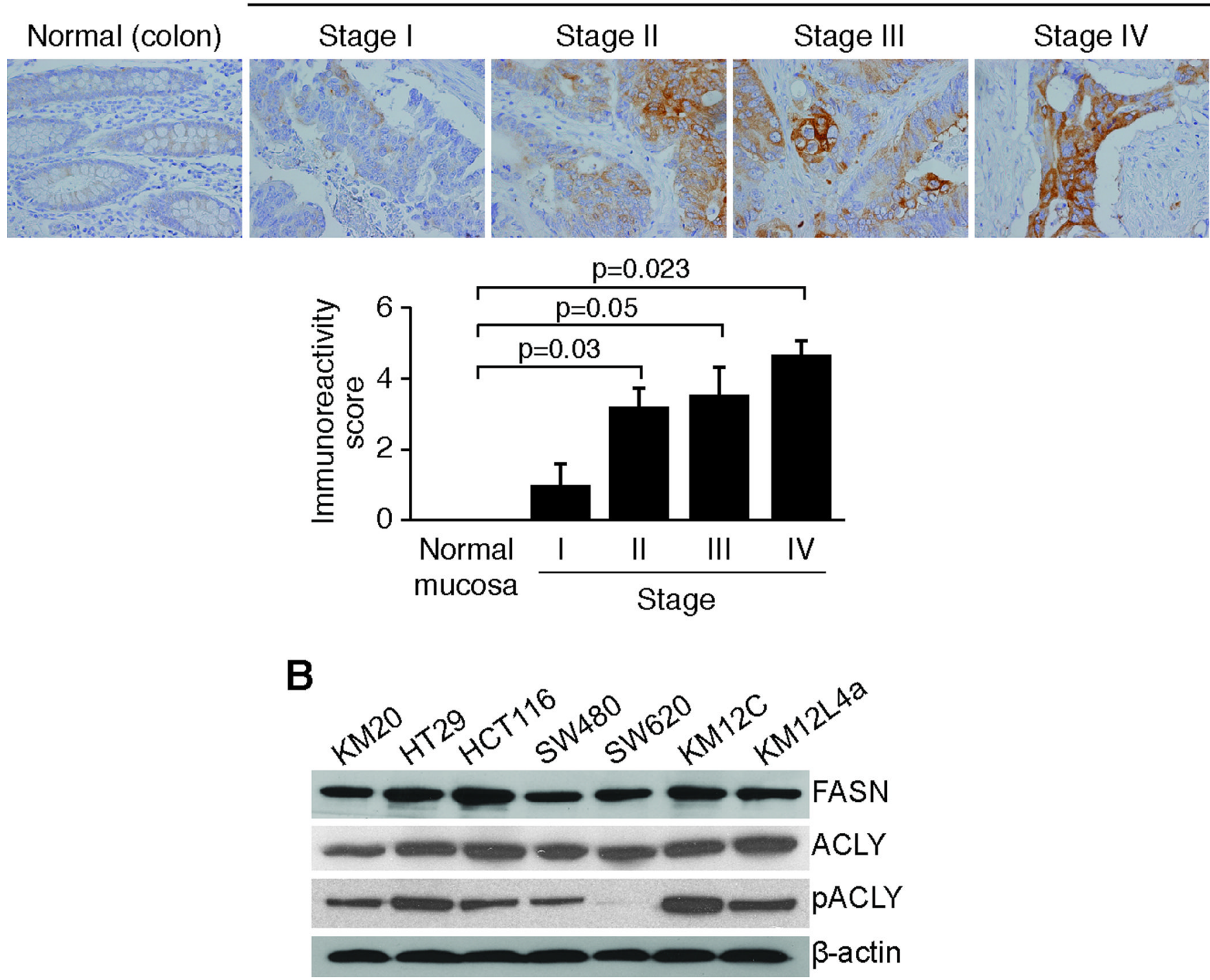

Figure 1.

Expression of FASN in CRC tissues and cell lines. A, expression of FASN in normal colon mucosa and Stage I-IV primary CRC (US Biomax tissue array CO702 (USA), total 69 cores, $\times 200$ magnification). Immunoreactivity score was determined according to a semiquantitive method as described in Materials and Methods. B, Cell lysises were prepared from a panel of human CRC cell lines and immunoblot analysis was performed for FASN, ACLY, and pACLY expression. $\beta$-actin was used as a loading control. 
A

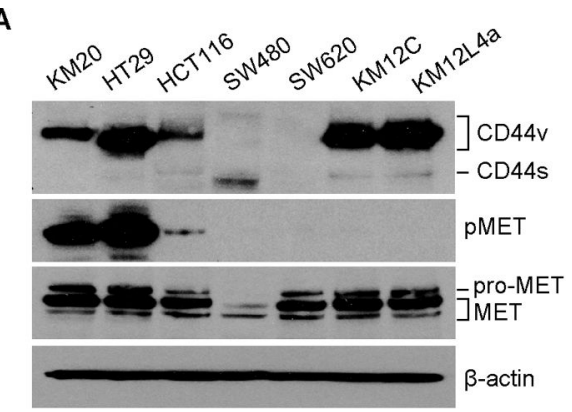

C

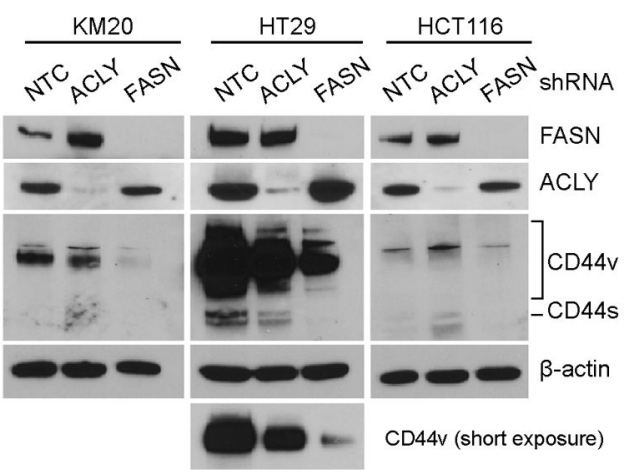

E

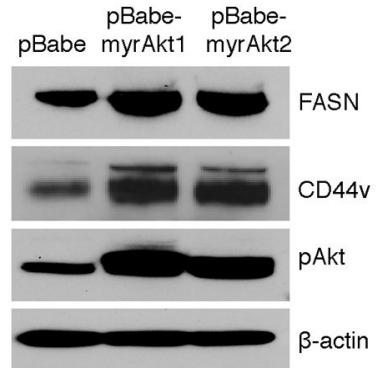

G

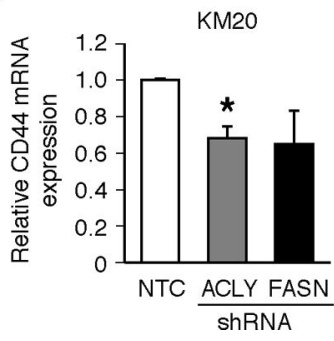

B
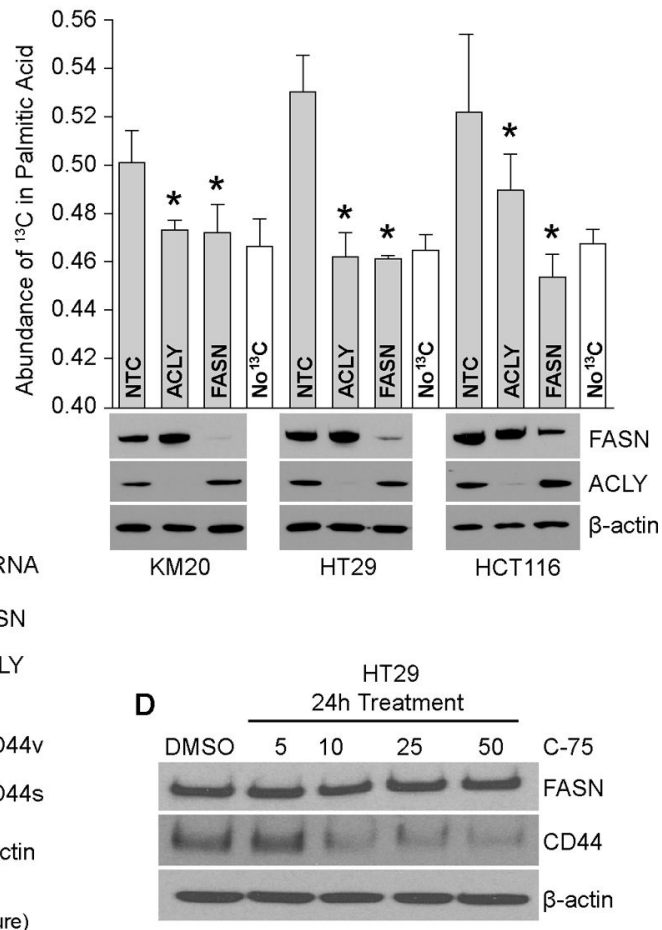

F

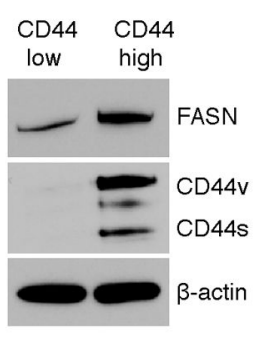

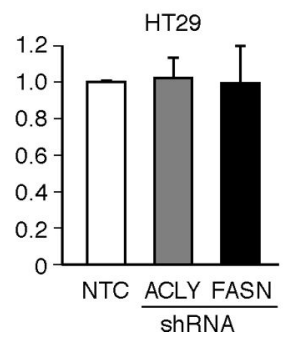

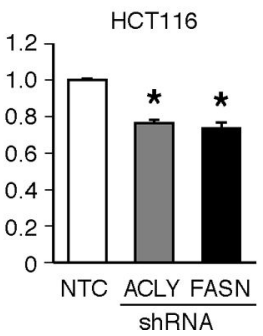

Figure 2.

Inhibition of ACLY and FASN attenuates expression of CD44. A, immunoblot analysis for CD44, p-MET, and total MET in a panel of CRC cell lines. $\beta$-actin was used as a loading control. B, de novo lipogenesis was analyzed by stable isotope labeling. Abundance of ${ }^{13} \mathrm{C}$ acetate in palmitic acid was determined in CRC cell lines with NTC shRNA, ACLY shRNA, and FASN shRNA by mass spectrometry. Data shown as the ratio of integrated peak areas (means $+/-\mathrm{SD}$ of triplicate determinations). No ${ }^{13} \mathrm{C}$ is an abundance of ${ }^{13} \mathrm{C}$ in unlabeled cells (a baseline isotope ratio). *, p $<0.05$ versus control. C, expression of CD44 in KM20, HT29, and HCT116 CRC cell lines with NTC shRNA, ACLY shRNA, and FASN shRNA. D, expression of CD44 in HT29 cell line treated with various concentrations of C-75 $(\mu \mathrm{M})$, 
an inhibitor of FASN, for $24 \mathrm{~h}$. E, expression of FASN and CD44 in HT29 cell line transiently transfected with myr-Akt1, myr-Akt2, or a control plasmid. F, immunoblot analysis for FASN and CD44 in HT29 FASN shRNA cells labeled with CD44-FITC antibody and sorted for expression of CD44. Cells with the lowest (10\%) and the highest (10\%) expression of CD44 were used for analysis. G, relative CD44 mRNA levels in KM20, HT29, and HCT116 cell lines with stable knockdown of ACLY or FASN assessed by realtime PCR. CD44 mRNA expression was calculated using the $\Delta \Delta \mathrm{Ct}$ method areas (means + / - SD of triplicate determinations, $* \mathrm{p}<0.05$ versus control). 


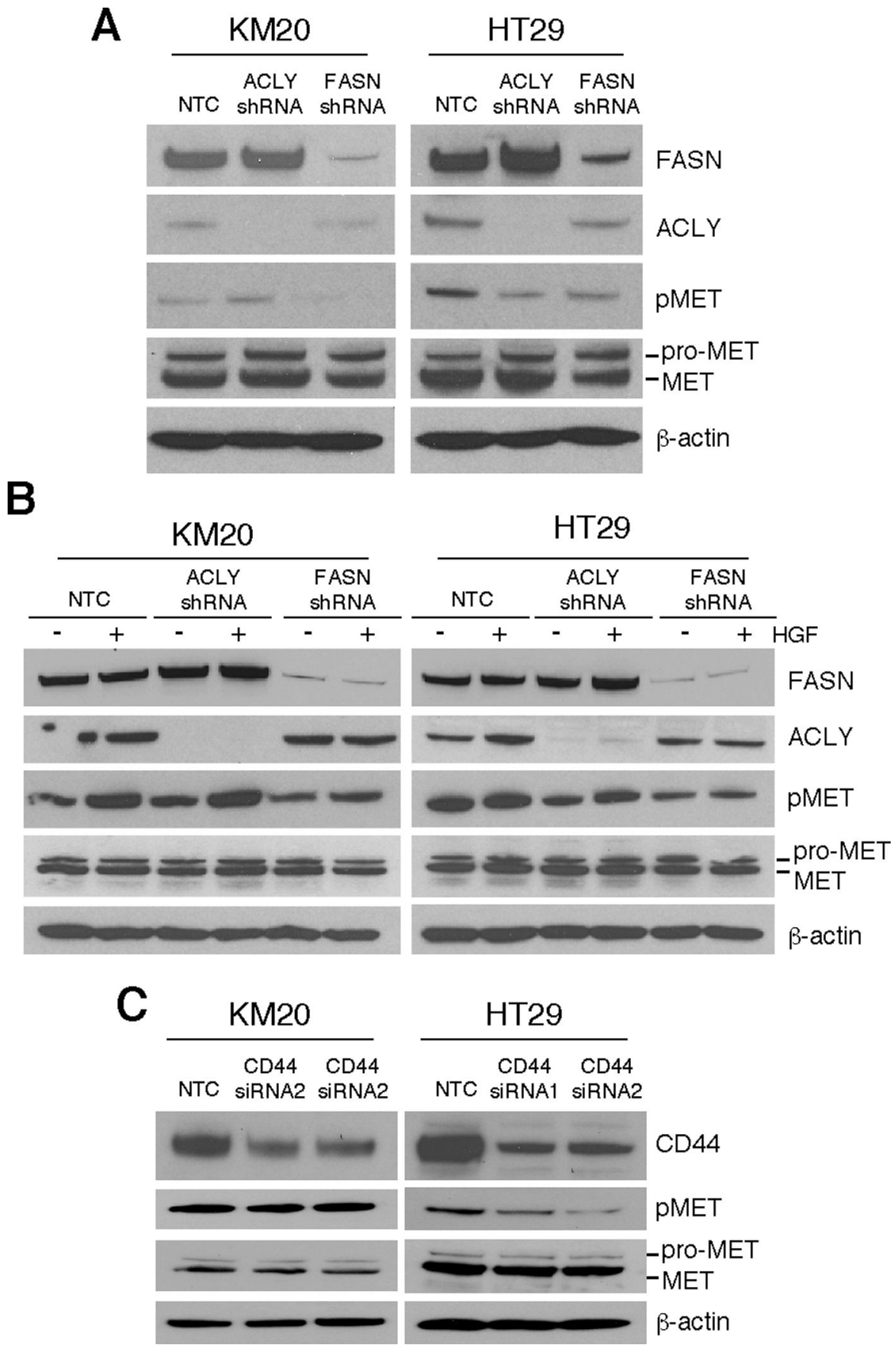

Figure 3.

Inhibition of ACLY and FASN attenuates c-MET signaling. A, Immunoblot analysis for pMET and MET in KM20 and HT29 cells lines with NTC shRNA, ACLY shRNA, and FASN shRNA. B, NTC shRNA, ACLY shRNA, and FASN shRNA KM20 or HT29 cells were starved for $24 \mathrm{~h}$, then stimulated with HGF $(10 \mathrm{ng} / \mathrm{ml})$ for $20 \mathrm{~min}$, lysed, and immunoblotted for FASN, ACLY, p-MET and MET. C, Immunoblot analysis for p-MET and MET expression in KM20 and HT29 cells lines transfected with two different CD44 siRNAs or scrambled siRNA as a control. 
A

C
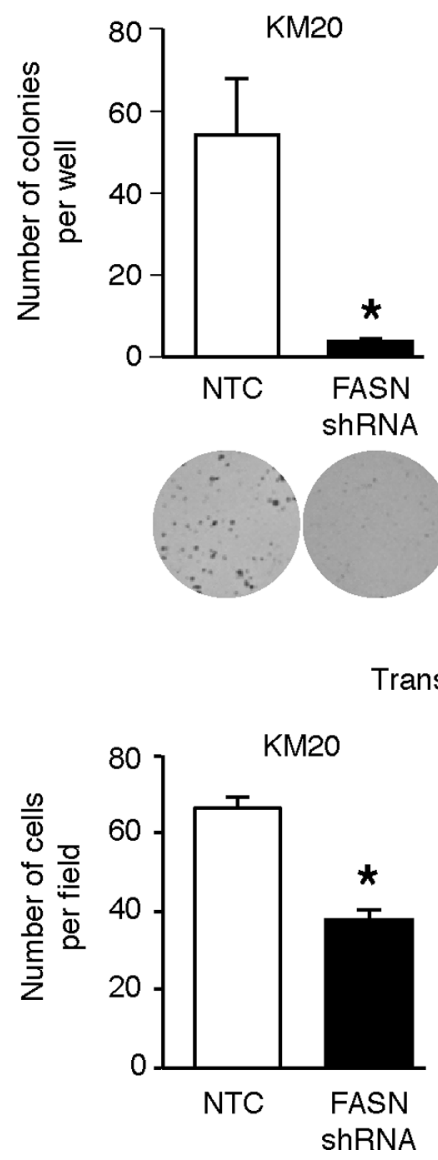

Figure 4.
Soft Agar Assay
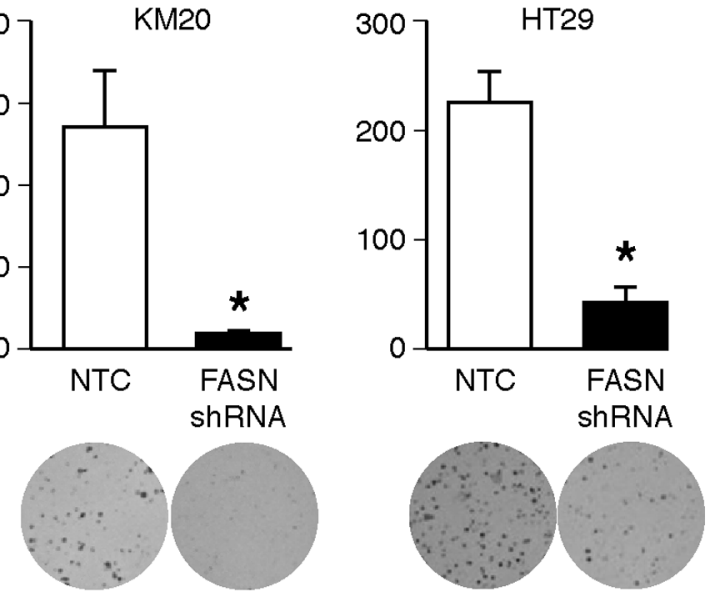

Transwell Migration

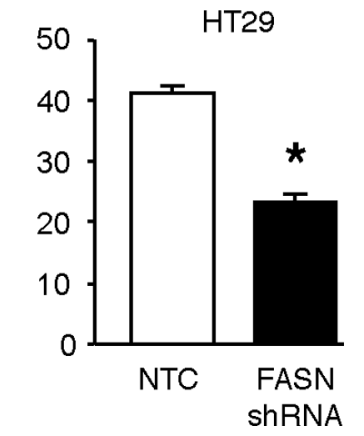

B
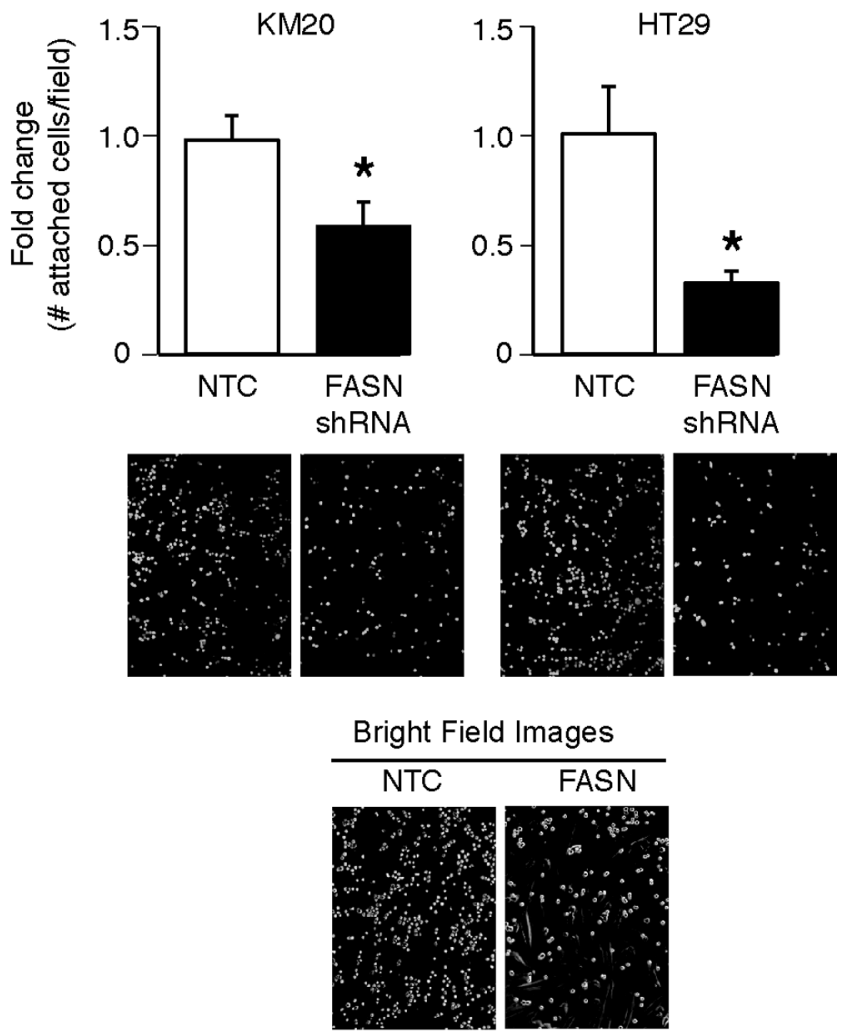

De novo lipid biosynthesis promotes tumorigenic potential of CRC cells. A, KM20 and HT29 cells with NTC shRNA and FASN shRNA were plated in soft agar and the number of colonies formed in each well was counted (day 20) using Alpha Innotech Imaging system and AlphaEase software. Data shown as difference in number of colonies formed in agar by control and FASN knockdown cells. Data are representative of three independent experiments. *, p $<0.05$ versus control. Images of representative wells are shown. B, KM20 and HT29 cells with NTC shRNA and FASN shRNA were added on top of an HMVEC-L monolayer and cell adhesion was assessed as described in Material and Methods. Data shown as mean fold changes in number of CRC cells with knockdown of FASN attached to HMVEC-L cells versus control cells $(*, p<0.05)$. Data are representative of three independent experiments. Representative images demonstrate adhesion of control and FASN knockdown cells to HMVEC-L cells. C, Transwell migration assay was carried out with KM20 and HT29 cells with NTC shRNA and FASN shRNA. Data shown as mean of cell number migrated per high-power field; *, p <0.05 versus control. Data are representative of three independent experiments. 
A

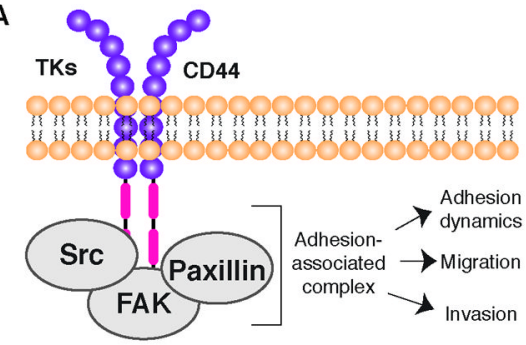

B

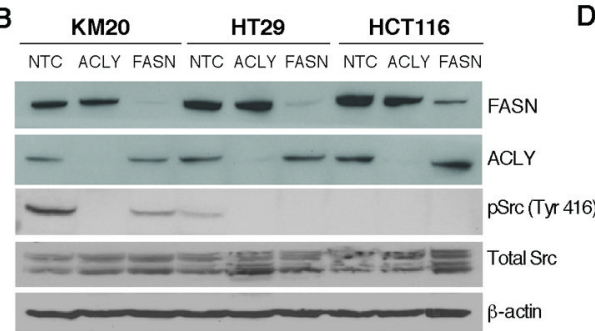

E

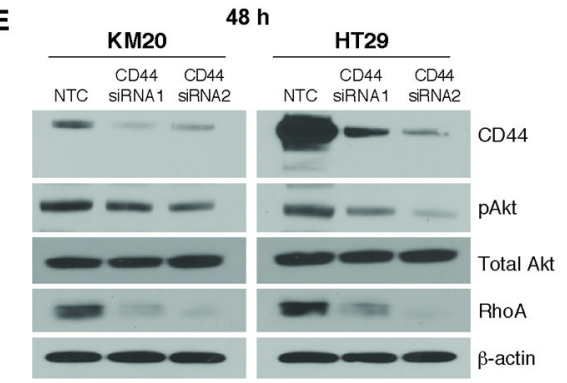

$\mathbf{F}$
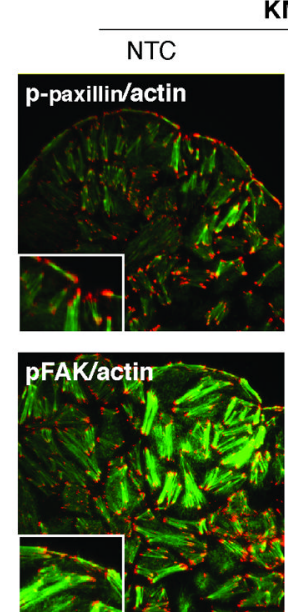

D

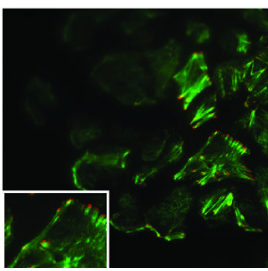

C
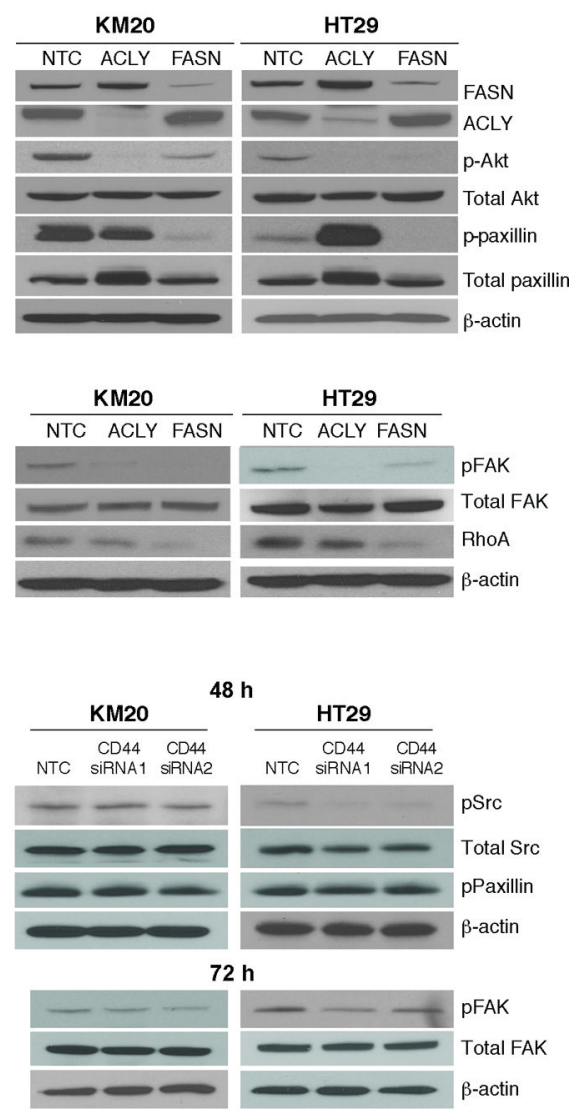

HT29
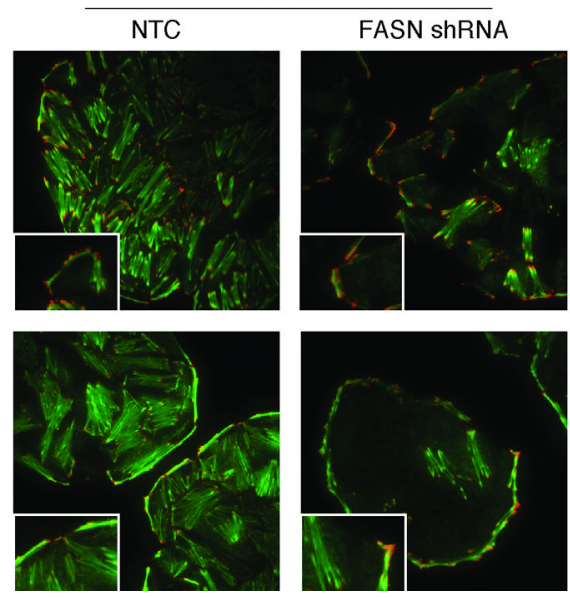

Figure 5.

Inhibition of de novo lipogenesis affects expression of proteins involved in regulation of cell adhesion, motility, and invasion and induces rearrangement of the actin cytoskeleton. A, schematic illustration of regulation of cell adhesion, migration and invasion by the CD44/cMET complex. B, immunoblot analysis for FASN, ACLY, pSrc, and total Src in KM20, HT29 cells, and HCT116 cell lines with NTC shRNA, ACLY shRNA, and FASN shRNA. C, immunoblot analysis for FASN, ACLY, pAkt, total Akt, p-paxillin, and total paxillin in KM20 and HT29 cells with NTC shRNA, ACLY shRNA, and FASN shRNA. D, immunoblot for pFAK, total FAK, and RhoA in KM20 and HT29 cells with NTC shRNA, ACLY shRNA, and FASN shRNA. E, Immunoblot analysis forp Akt, RhoA, pSrc, p- 
paxillin, and p-FAK in KM20 and HT29 cells lines transfected with two different CD44 siRNAs or scrambled siRNA as a control for $48 \mathrm{~h}$ or 72 hours. F, total internal reflection fluorescence imaging of control and FASN knockdown KM20 and HT29 cells stained for Factin (green) and either p-paxillin (red) or pFAK (red). 
A

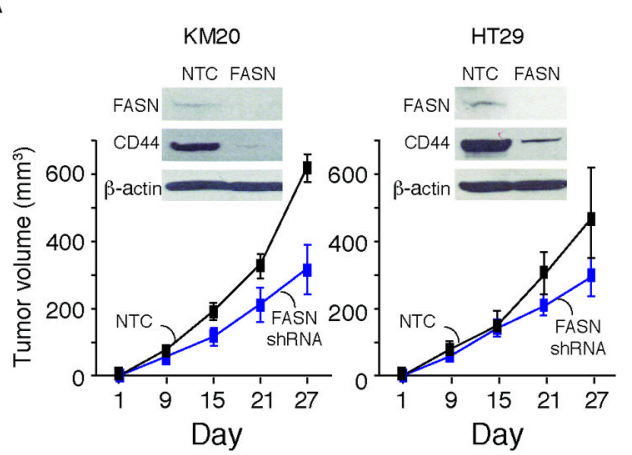

C

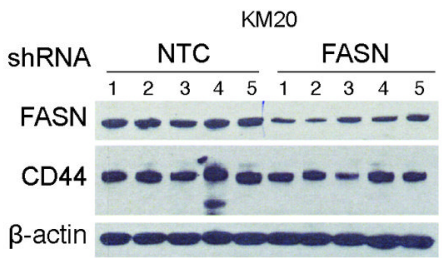

D
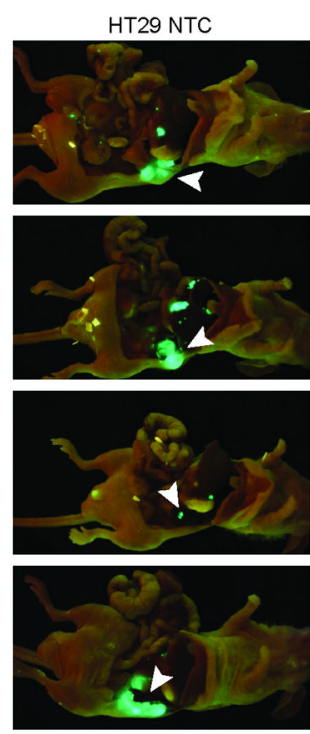

HT29 FASN ShRNA
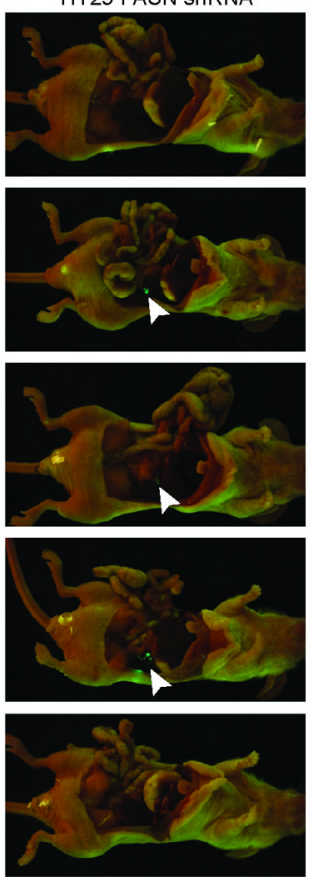

Figure 6.
B
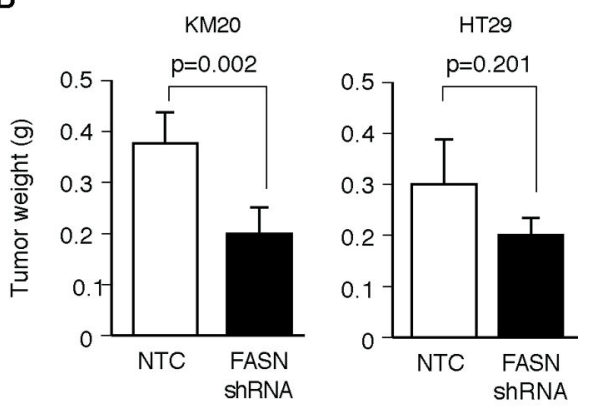

$\mathbf{E}$
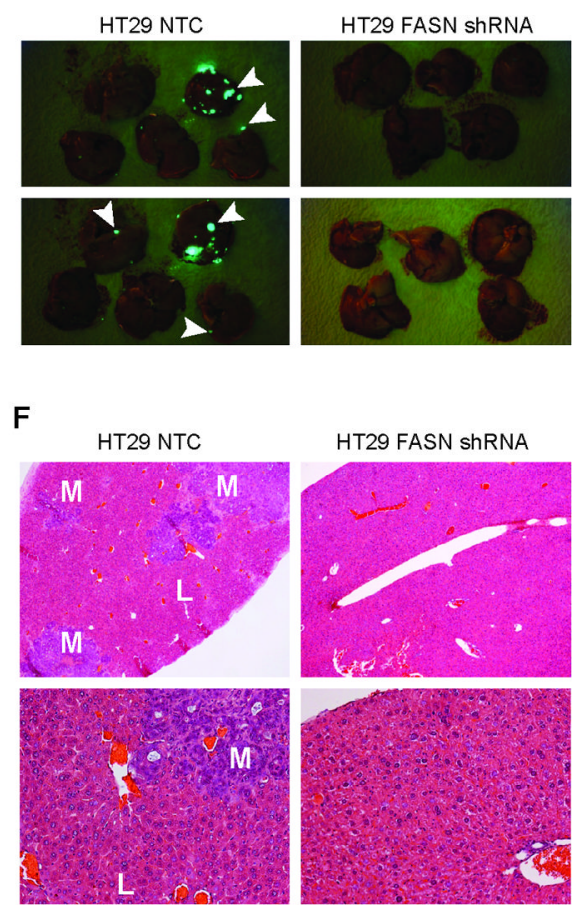

HT29 FASN ShRNA
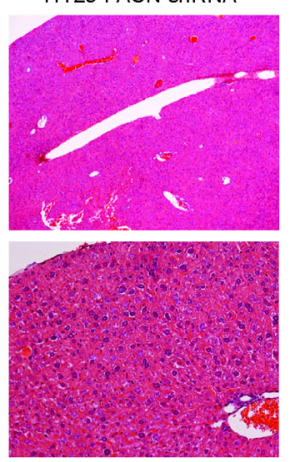

Inhibition of FASN suppresses primary CRC tumor growth and establishment of liver metastasis. A, KM20 and HT29 cells $\left(1 \times 10^{6}\right.$; NTC or FASN shRNA) were injected subcutaneously into athymic nude mice. Immunoblot analysis for FASN and CD44 in tumor cells prior to injections shown with tumor volume for days 1-27 (5 mice per group). B, tumor weights in control and FASN shRNA groups of KM20 and HT29 xenografts. C, immunoblot analysis for FASN and CD44 in tumor tissues from KM20 and HT29 xenograft (day 27). D, images of GFP-positive cancer cells in athymic nude mice injected intrasplenically with HT29-NTC-Luc/GFP or HT29-FASNshRNA-Luc/GFP cells (abdominal view). Arrows heads indicate primary tumors. E, images of GFP-positive cells in 
liver. F, representative images of histological analysis (H\&E staining) of liver metastasis (L, normal liver; $\mathrm{M}$, metastasis). 
A

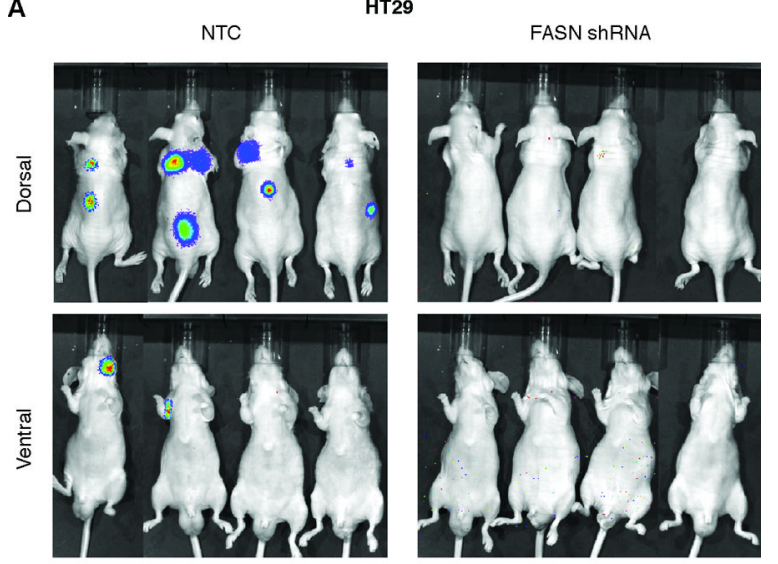

B

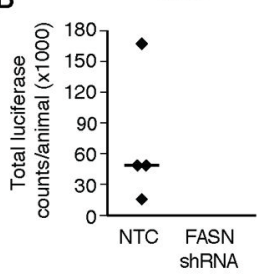

C NTC $\stackrel{\text { HT29 }}{\text { FASN ShRNA }}$
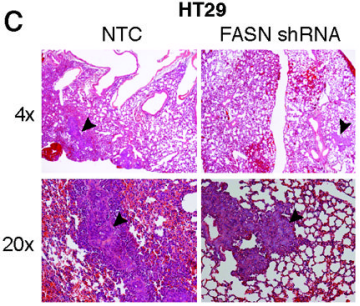

KM20

D

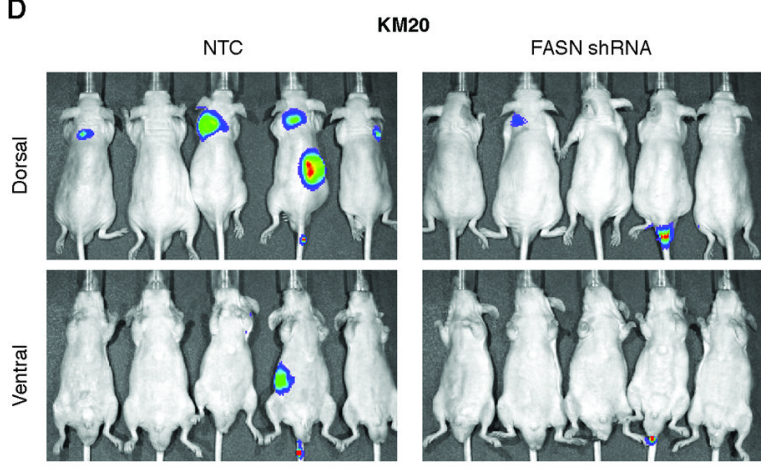

E
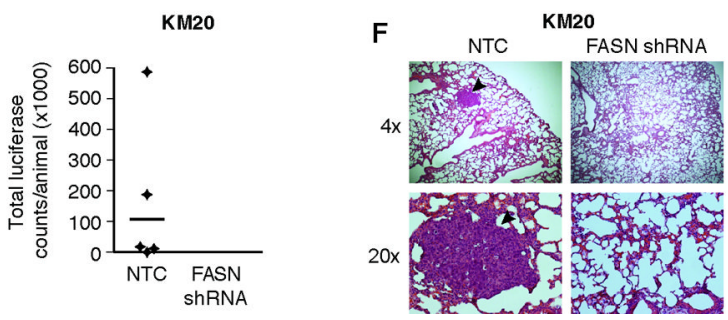

Figure 7.

Inhibition of FASN prevents establishment of CRC metastasis. A, in vivo total-body bioluminescence images of athymic nude mice in dorsal and ventral positions (IVIS@ Imaging System) injected i.v. with HT29-NTC-Luc or HT29-FASNshRNA-Luc cells. B, quantitative analysis of metastasis (estimated by total luciferase counts per animal) in athymic nude mice injected i.v. with HT29-NTC-Luc or HT29-FASNshRNA-Luc cells. C, representative images of histological analysis of lung micrometastasis in mice injected i.v. with HT29-NTC-Luc or HT29-FASNshRNA-Luc cells. D, in vivo total-body bioluminescence images of athymic nude mice in dorsal and ventral positions (IVIS @ Imaging System) injected i.v. with KM20-NTC-Luc/GFP or KM20-FASNshRNA-Luc/GFP 
cells. E, quantitative analysis of metastasis (estimated by total luciferase counts per animal) in athymic nude mice injected i.v. with KM20-NTC-Luc/GFP or KM20-FASNshRNA-Luc/ GFP cells. F, representative images of histological analysis (H\&E staining) of lung micrometastasis in athymic nude mice injected i.v. with KM20-NTC-Luc/GFP or KM20FASNshRNA-Luc/GFP cells. 